\title{
ÍNDICES MORFO-FISIOLÓGICOS E RENDIMENTO DA ALFACE (Lactuca sativa L.) EM AMBIENTES NATURAL E PROTEGIDO ${ }^{1}$
}

\author{
Renilson Targino Dantas ${ }^{2}$ e João Francisco Escobedo ${ }^{3}$
}

\begin{abstract}
RESUMO
Dois experimentos foram conduzidos para se avaliar e comparar o crescimento e rendimento da alface na área experimental do Departamento de Física e Biofísica do Instituto de Biociências da Universidade Estadual Paulista, Campus de Botucatu (22 $54^{\prime}$ 'S; $48^{\circ} 27^{\prime} \mathrm{W} ; 850 \mathrm{~m}$ ), no verão de 1995/96 e no inverno de 1996, consistindo de três parcelas com dimensões de $7 \mathrm{~m}$ x 5m, sendo duas situadas em ambientes protegidos, tipo túnel, nas direções Leste-Oeste e Norte-Sul, e a outra parcela em condições naturais ou externas. A taxa de crescimento absoluto, no verão, foi de $5,22 \mathrm{~g} / \mathrm{semana}$ nos ambientes protegidos, e de 3,97 $\mathrm{g} / \mathrm{semana}$ na parcela externa, e no inverno esses valores foram de 3,02 e $2,85 \mathrm{~g} / \mathrm{semana}$. A taxa de assimilação líquida sofreu mais efeitos dos ambientes protegidos que da época do ano e a taxa de crescimento da cultura evidenciou que a cobertura do solo pelas plantas nos ambientes protegidos foi mais rápida. Conforme os resultados obtidos do rendimento, pode-se afirmar que existiu influência dos ambientes protegidos nas duas épocas do ano, com pequena vantagem no inverno.
\end{abstract}

Palavras-chave: crescimento, massa seca, área foliar, casas de vegetação

\section{MORPHOLOGICAL AND PHYSIOLOGICAL INDICES AND LETTUCE (Lactuca sativa L.) YIELD IN NATURAL AND PROTECTED AMBIENTS}

\begin{abstract}
The objective of this research was to evaluate and to compare the growth and yield of lettuce. Two experiments were conducted in the experimental area of Physics and Biophysics Department of the Biosciences Institute of Paulista State University, Botucatu Campus (22 $54^{\circ}$ 'S; 48 $27^{\prime}$ 'W; 850m) in the summer of 1995/96 and winter of 1996, with three plots of $7 \mathrm{~m} \times 5 \mathrm{~m}$, where two were located in the greenhouse (tunnel type), in the East-West and North-South directions, and the other plot under natural or external conditions. The absolute growth rate in the summer was 5.22 g.week $^{-1}$ in the greenhouse, and 3.97 g.week $^{-1}$ in the external plot, while in winter these values were 3.02 e 2.8 g.week ${ }^{-1}$. The net assimilation rate suffered more influence from greenhouse conditions than from year period. The crop growth rate showed clearly that under greenhouse conditions the growth rate was quicker. According to the yield results, it is concluded that the protected environments had a influence in the two-year periods, with little advantage for the winter.
\end{abstract}

Key words: growth, dry weight, leaf area, greenhouse

\footnotetext{
${ }^{1}$ Parte da Tese de Doutorado do primeiro autor

2 Professor Adjunto, Doutor, DCA/CCT/UFPB, CP 1034, Campina Grande, PB

3 Professor Adjunto, Doutor, DCA/FCA/UNESP, CP 237, Botucatu, SP
} 


\section{INTRODUÇÃO}

A produtividade primária de uma cultura é, em última análise, o resultado da relação fotossíntese/respiração, expressa pela eficiência fotossintética sendo, portanto, necessário o conhecimento dos mecanismos pelos quais se dá a interação solo-planta-atmosfera, de forma que se deve investigar melhor o uso racional e a otimização do microclima. O uso de modelos matemáticos para expressar o crescimento e seus parâmetros derivados, como taxa de crescimento relativo, taxa de assimilação líquida e outros é, atualmente, muito popular, e pode, eventualmente, fornecer subsídios para melhor compreensão dos diferentes processos fisiológicos envolvidos na morfogênese da planta.

Hoje, a disponibilidade de algoritmos para ajuste de funções não lineares viabiliza o uso de modelos matemáticos para análise de crescimento. Em geral, modelos envolvendo maior número de parâmetros são mais flexíveis e possibilitam melhor ajuste (Causton \& Venus, 1981). Milthorpe (1986) assinala a importância da área foliar como fator que influi na taxa de crescimento e minimiza a importância da taxa fotossintética; entretanto, Stoy (1983) salienta que a taxa fotossintética pode ser muito importante na determinação das taxas de crescimento. O objetivo deste trabalho foi determinar os índices de crescimento e avaliar o rendimento da alface, sob influência de ambiente aberto e de casa de vegetação.

\section{MATERIAL E MÉTODOS}

Os experimentos foram conduzidos na área experimental do Departamento de Física e Biofísica do Instituto de Biociências da Universidade Estadual Paulista, Campus de Botucatu (22 $2^{\circ} 4^{\prime} \mathrm{S} ; 48^{\circ} 27^{\prime} \mathrm{W}$; $\left.850 \mathrm{~m}\right)$ consistindo de três parcelas com dimensões de $7 \mathrm{~m}$ x 5m, sendo duas delas situadas em ambientes protegidos (AP) com cobertura de polietileno, nas direções Leste-Oeste (L-O) e Norte-Sul (N-S) e a outra parcela em condições naturais ou externas (EXT).

O primeiro experimento (EXP I ou EXP de Verão) e o segundo (EXP II ou EXP de Inverno) foram realizados de acordo com o cronograma abaixo):

\begin{tabular}{cccc}
\hline & & \multicolumn{2}{c}{ Colheitas } \\
\cline { 3 - 4 } Semeadura & Transplante & Ambientes protegidos & Parcela externa \\
\hline $13 / 11 / 95$ & $06 / 12 / 95$ & $16 / 01 / 96$ & $27 / 01 / 96$ \\
$16 / 05 / 96$ & $11 / 06 / 96$ & $19 / 07 / 96$ & $29 / 07 / 96$ \\
\hline
\end{tabular}

Semanalmente e sempre no mesmo dia, a fim de se investigar o crescimento da alface, cultivar ELISA, foram determinadas a massa seca (MS), pelo processo de secamento em estufas a aproximadamente $75^{\circ} \mathrm{C}$, até atingir massa constante sendo, em seguida, utilizada a balança eletrônica com precisão de $0,01 \mathrm{~g}$ e a área foliar (AF) por meio do medidor de área foliar, modelo AAM-7 da Hayashi Denkoh.

Com base nessas informações determinou-se, durante cada experimento e em cada parcela, a taxa de crescimento absoluto (TCA) levando-se em consideração a variação da massa seca com o tempo; a taxa de crescimento relativo (TCR) expresso também em função da variação da massa seca; a taxa de assimilação líquida (TAL) que expressa a fotossíntese líquida, em termos de matéria seca produzida pela área foliar no intervalo de duas amostragens; a área foliar específica (AFE) componente morfológica e anatômica, capaz de relacionar a superfície das folhas com a sua massa seca, e a taxa de crescimento da cultura (TCC) que correlaciona o índice de área foliar com a taxa de assimilação líquida, expressando a produção de massa seca em relação à área cultivada; matematicamente, pode-se representá-los como (Blackman, 1968):

$$
T C A=\frac{P_{2}-P_{1}}{t_{2}-t_{1}}
$$

em que $\mathrm{P}_{2}-\mathrm{P}_{1}$ é a diferença de matéria seca $(\mathrm{g})$ entre duas amostragens e $t_{2}-t_{1}$ é o intervalo de tempo entre duas amostragens. Tem-se:

$$
\begin{gathered}
T C R=\frac{l u P_{2}-l u P_{1}}{t_{2}-t_{1}} \\
T A L=\frac{P_{2}-P_{1}}{t_{2}-t 1} \cdot \frac{l u A_{2}-l u A_{1}}{A_{2}-A_{1}}
\end{gathered}
$$

sendo $A_{1}$ e $A_{2}$ as áreas foliares no intervalo das amostragens. Tem-se:

$$
A F E=\frac{\text { area foliar }}{\text { massa seca das folhas }}
$$

$$
T C C=I A F x T A L
$$

sendo IAF o índice de área foliar.

A análise estatística foi feita comparando-se as médias dos índices morfo-fisiológicos de crescimento e desenvolvimento e, também, de rendimento, entre os ambientes protegidos e a parcela externa no mesmo experimento, e entre os experimentos, através do teste $\mathrm{t}$.

\section{RESULTADOS E DISCUSSÃO}

A Figura 1 mostra que no EXP I o máximo da taxa de crescimento absoluto ocorreu aos 36 dias após o transplante (DAT) em todas as situações. No EXP II esse máximo variou de 30 DAT no AP (L-O), até 44 DAT na parcela externa. No EXP I, o maior crescimento da TCA foi verificado de 29 a 36 DAT nas três condições, com destaque para a parcela externa, que teve um crescimento maior nesse período.

No mesmo experimento percebe-se através da Figura 1, que houve decréscimo geral da TCA de 36 a 43 DAT. No EXP II o maior crescimento da TCA foi verificado de 22 a 29 DAT nos ambientes protegidos, e de 29 a 36 DAT na parcela externa. Nos dois períodos experimentais os maiores valores, assim como os maiores decréscimos da TCA, foram encontrados no AP $(\mathrm{N}-\mathrm{S})$.

A TCA média no EXP I foi de $5,22 \mathrm{~g} / \mathrm{semana}$ nos ambientes protegidos, ocorrida aos $31 \mathrm{DAT}$, e de 3,97 g/semana na parcela externa, ocorrida também aos 31 DAT, o que representa uma diferença de $31 \%$. No EXP II a TCA média foi de $3,02 \mathrm{~g} / \mathrm{semana}$ nos ambientes protegidos, verificada aos $27 \mathrm{DAT}$, e de 2,85 g/semana, na parcela 


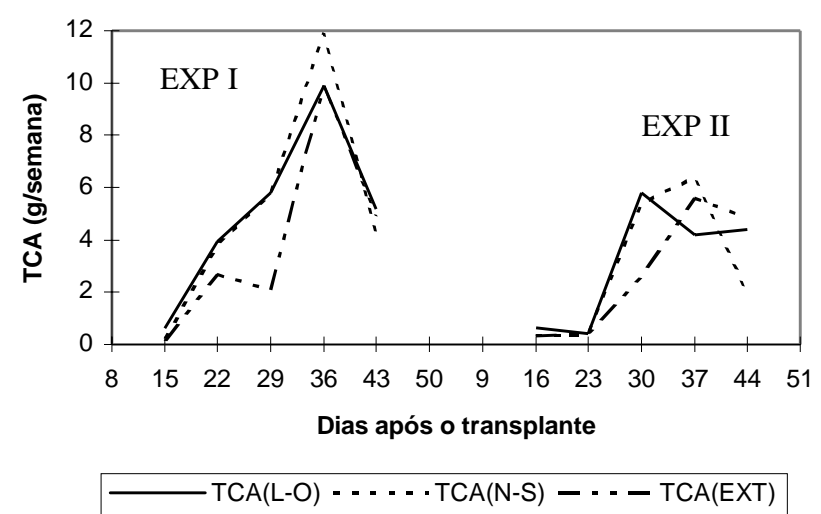

Figura 1. Variação da Taxa de Crescimento Absoluto (TCA) em função dos Dias Após o Transplante (DAT)

externa, ocorrida aos 31 DAT, o que indica uma diferença de apenas $6 \%$ aproximadamente. Esses resultados mostram que, em média, houve uma superioridade da TCA no verão de aproximadamente $56 \%$ em relação à TCA no inverno.

Houve diferença significativa a nível de $5 \%$ de probabilidade entre a TCA do AP (N-S) e a TCA da parcela externa no EXP I. No EXP II não foi constatada nenhuma diferença significativa da TCA entre as condições estudadas, mas quando comparada a TCA das condições estudadas entre os experimentos, houve diferença significativa no AP (N-S) a nível de 5\% de probabilidade.

Na Figura 2 constata-se que os máximos valores da taxa de crescimento relativo ocorreram aos 22 DAT e 16 DAT, em todas as condições dos experimentos I e II, respectivamente, e os maiores acréscimos e decréscimos da TCR ocorreram no AP (N-S) no EXP I, e no AP (L-O) no EXP II. Os mínimos valores da TCR no EXP I foram praticamente os mesmos, com ligeira superioridade na parcela externa, no final do experimento. $\mathrm{O}$ mesmo comportamento pode ser verificado também no EXP II, com inversão no AP (N-S). As características que mais chamam a atenção na Figura 2 é que, nas terceira e quarta semanas após o transplante, as curvas representativas da TCR se invertem nas duas épocas, o que esclarece o fato de que as plantas relativamente crescem e se desenvolvem em função da matéria seca armazenada e das condições do meio ambiente para a produção de novo material estrutural.

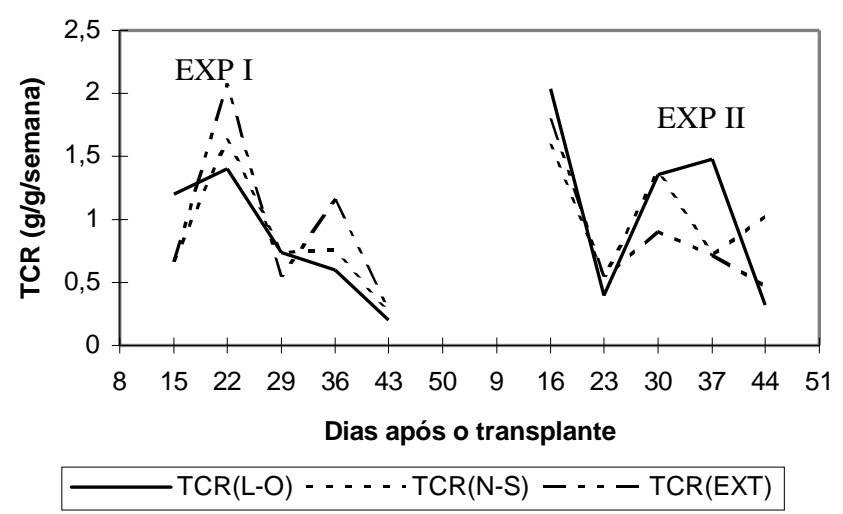

Figura 2. Taxa de Crescimento Relativo (TCR) em função dos Dias Após o Transplante (DAT)
A análise de crescimento estabelece que a taxa de crescimento de uma planta ou de qualquer órgão da planta é uma função do tamanho inicial, isto é, o aumento da matéria seca está relacionado à matéria seca no início do período de observação (Benincasa, 1988).

A TCR média no verão foi de $0,86 \mathrm{~g} / \mathrm{semana}$ nos ambientes protegidos e de $0,94 \mathrm{~g} / \mathrm{semana}$ na parcela externa. No inverno, a TCR média foi de $1,08 \mathrm{~g} / \mathrm{semana}$ nos ambientes protegidos e de $0,90 \mathrm{~g} / \mathrm{semana}$ na parcela externa. No verão, de acordo com esses dados, houve superioridade externa de aproximadamente $9 \%$, enquanto no inverno essa superioridade foi dos ambientes protegidos, em torno de $20 \%$; da mesma forma, foi revelado que, de maneira geral, a TCR média do inverno superou a TCR média do verão em $10 \%$.

Quando as TCR nos EXP I e EXP II foram comparadas estatisticamente, verificou-se não haver nenhuma diferença significativa; comparando-se, também, as TCR entre os experimentos, não houve efeito da época do ano.

Na Figura 3 estão mostradas as curvas da área foliar específica de todas as situações. No verão, os máximos valores da AFE ocorreram na quarta semana após o transplante nos ambientes protegidos, assim como na parcela externa, com destaque maior para o AP $(\mathrm{N}-\mathrm{S})$ que atingiu o valor máximo absoluto. Observa-se também que as curvas do AP (N-S) e da parcela externa comportaram-se de forma semelhante. $\mathrm{Na}$ segunda semana após o transplante, o crescimento da matéria seca no AP (L-O) foi maior que o crescimento da área foliar, fato este comprovado pela inversão da curva em relação às demais. Constata-se, na mesma Figura que, de maneira geral, nessa época do ano o crescimento da matéria seca foi maior que o crescimento da área foliar a partir dos 29 DAT.

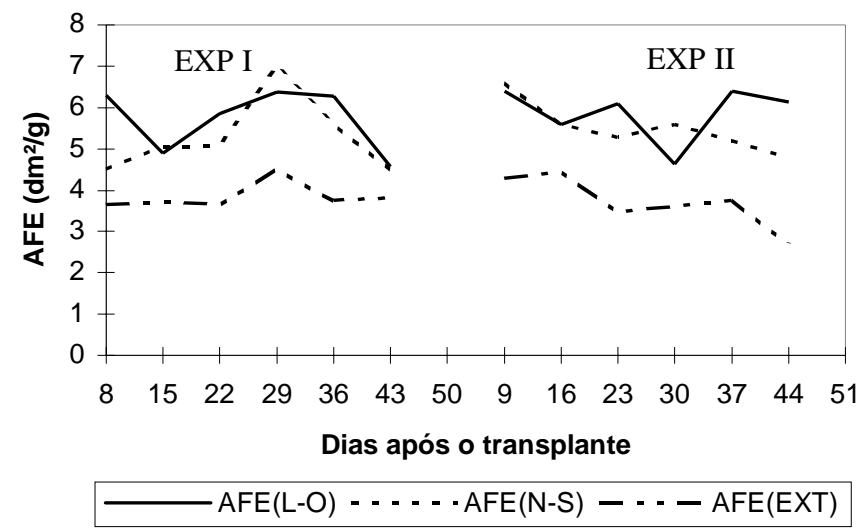

Figura 3. Curvas da Área Foliar Específica (AFE) em função dos Dias Após o Transplante (DAT)

No inverno e no verão, os valores da AFE nos ambientes protegidos foram sempre superiores ao valores da AFE na parcela externa e, com exceção das últimas semanas após o transplante, os comportamentos foram geralmente inversos. Desta forma, tanto no verão como no inverno, o crescimento da área foliar foi menor que o crescimento da matéria seca na última semana após o transplante.

A evolução dos parâmetros de crescimento e desenvolvimento mostra que o efeito dos ambientes protegidos se exerce sobretudo sobre a velocidade de crescimento das plantas, porém a análise de crescimento das folhas, caule e raízes mostra, que a temperatura influencia os diferentes órgãos da 
planta de maneira distinta durante o período de desenvolvimento (Segovia et al., 1997).

Fica comprovado que as folhas externas aos ambientes protegidos mostraram-se com menor conteúdo líquido e, conseqüentemente, mais espessas, pois a média da AFE no verão nos ambientes protegidos foi de $5,63 \mathrm{dm}^{2} / \mathrm{g}$ e, na parcela externa, de $3,96 \mathrm{dm}^{2} / \mathrm{g}$, valores estes semelhantes aos do inverno que foram, em média, de $5,64 \mathrm{dm}^{2} / \mathrm{g}$ e $3,92 \mathrm{dm}^{2} / \mathrm{g}$ nos referidos locais.

Análises estatísticas da AFE revelaram que existiram diferenças significativas a nível de $1 \%$ de probabilidade entre os ambientes protegidos e a parcela externa nos dois experimentos, não havendo, portanto, diferença significativa da AFE entre os ambientes protegidos em nenhum período experimental. No mesmo sentido, foi revelado que não houve efeito da época do ano na AFE em nenhuma situação.

A Figura 4 mostra o comportamento da taxa de assimilação líquida nos dois períodos experimentais. No verão, a TAL foi máxima aos 21 DAT em todas as condições, sendo absolutamente maior na parcela externa. Os mínimos valores da TAL ocorreram no final do experimento, também nas três condições. Nesta Figura verifica-se, ainda, que de 22 aos 29 DAT houve decréscimo geral na TAL, o que expressa diminuição global na taxa de fotossíntese, convergindo para um único ponto do gráfico. $\mathrm{O}$ comportamento da TAL nos ambientes protegidos foi representado de forma muito semelhante, com pequena superioridade do AP (N-S) . Os mínimos valores da TAL foram verificados nos últimos dias após o transplante em todas as condições, o que evidencia uma baixa taxa de produção de matéria seca no final do experimento.

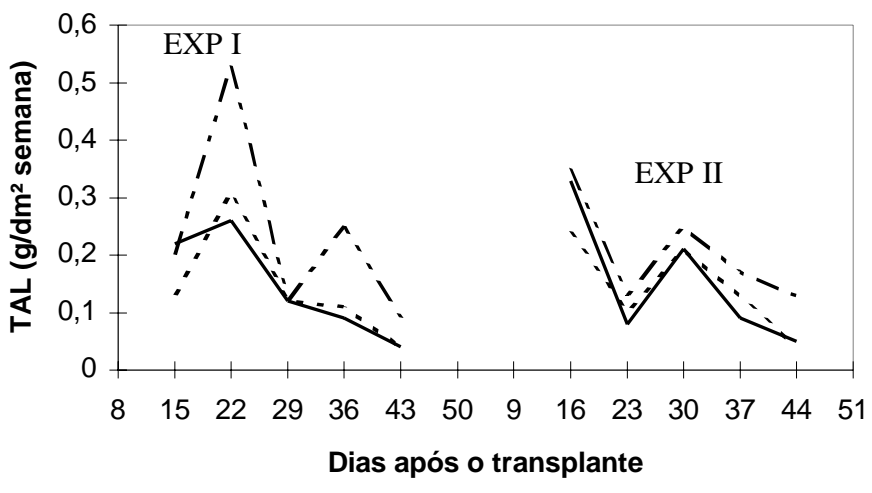

TAL(L-O) - . . . - TAL(N-S) - . - TAL(EXT)

Figura 4. Comportamento da Taxa de Assimilação Líquida (TAL) em função dos Dias Após o Transplante (DAT)

No inverno constata-se, através da Figura 4, que as curvas representativas das condições estudadas são, evidentemente, semelhantes, apenas com leve superioridade da parcela externa, principalmente no término do período experimental. Os valores médios da TAL no verão foram de $0,156 \mathrm{~g} / \mathrm{dm}^{2} / \mathrm{semana}$ nos ambientes protegidos e de $0,244 \mathrm{~g} / \mathrm{dm}^{2} / \mathrm{semana}$ na parcela externa. Esses valores corresponderam a $0,155 \mathrm{~g} / \mathrm{dm}^{2} / \mathrm{semana}$ e a $0,220 \mathrm{~g} / \mathrm{dm}^{2} / \mathrm{semana}$ no inverno. Uma das diferenças básicas existentes entre os períodos experimentais em relação a TAL é que, no verão, o maior crescimento da matéria seca em razão da área foliar ocorreu na terceira semana após o transplante e, no inverno em função da diminuição da temperatura ao longo dos DAT; este fato verificou-se na segunda semana após o transplante.
No EXP I houve diferença significativa da TAL no AP (N-S) e da TAL na parcela externa a nível de $5 \%$ de probabilidade. No EXP II não houve diferença significativa, apenas entre os ambientes protegidos. Quando se comparou a TAL entre os experimentos, verificou-se não haver efeito da estação do ano.

$\mathrm{Na}$ Figura 5 apresentam-se as curvas de variação temporal e condicional da taxa de crescimento da cultura. No EXP I, com exceção do comportamento da TCC externa, na quarta semana após o transplante as curvas se identificaram do início até o final do referido experimento, mostrando crescimento absoluto das plantas até os 36 DAT.

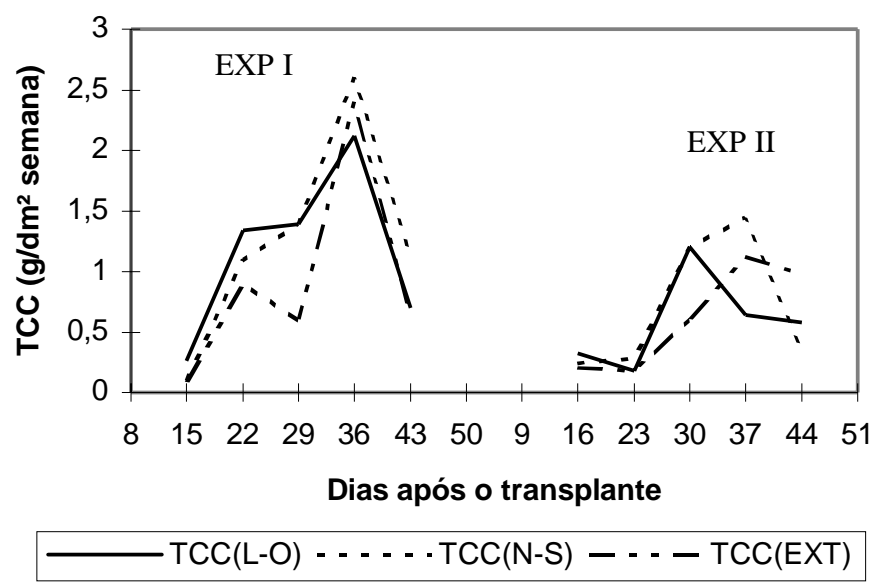

Figura 5. Curvas de variação da Taxa de Crescimento da Cultura (TCC) em relação aos Dias Após o Transplante (DAT)

O maior incremento da TCC ocorreu na terceira semana após o transplante no AP (L-O) e na quinta semana após o transplante, nas outras condições. Este fato foi relevante no que se refere à cobertura do solo pela cultura, tendo mostrado que no AP (L-O) esta cobertura foi mais rápida. Como era de se esperar, houve decréscimo geral da TCC, a partir dos 36 DAT evidenciando-se, assim, a aproximação do ponto de colheita.

No EXP II o comportamento das curvas da TCC foi semelhante até a quarta semana após o transplante e, a partir daí, houve distinção da curva representativa do AP (L-O) no sentido da mesma decrescer até os 44 DAT. Este decréscimo nos valores da TCC ocorreu no AP $(\mathrm{N}-\mathrm{S})$ e na parcela externa, uma semana depois. Está caracterizado, também na Figura 5, que no inverno os maiores incrementos da TCC ocorreram na quarta semana após o transplante e que, ainda nesta mesma semana, a cobertura do solo pela cultura foi maior nos ambientes protegidos.

Constata-se, por intermédio desta Figura, que a TCC geralmente foi maior no verão, apresentando médias de 1,196 $\mathrm{g} / \mathrm{dm}^{2} / \mathrm{semana}$ nos ambientes protegidos e de $0,988 \mathrm{~g} / \mathrm{dm}^{2} / \mathrm{semana}$ na parcela externa. No inverno esses valores foram de 0,707 $\mathrm{g} / \mathrm{dm}^{2} /$ semana e de $0,618 \mathrm{~g} / \mathrm{dm}^{2} / \mathrm{semana}$, respectivamente. Desta forma e considerando-se esses resultados, percebeu-se superioridade da TCC no verão, de aproximadamente $69 \%$ nos ambientes protegidos e de $60 \%$ na parcela externa, refletindo demasiadamente no rendimento final da cultura.

A partir dos dados de crescimento pode-se inferir atividade fisiológica, isto é, estimar-se, de forma bastante precisa, as causas de variações de crescimento entre plantas geneticamente diferentes ou entre plantas crescendo em ambientes diferentes (Benincasa, 1988). 
Comparando-se estatisticamente os dados da TCC, constatou-se que em nenhum dos casos houve diferença significativa; o mesmo sucedeu quando comparados os dados da TCC entre os períodos experimentais.

A Tabela 1 mostra os valores de rendimento obtidos nos dois experimentos, nas três condições. No verão, verificou-se que a diferença entre os ambientes protegidos foi muito pequena, menos de $1 \%$, e que, em média, os mesmos superaram a parcela externa em aproximadamente $48 \%$; no inverno, a diferença de rendimento entre os ambientes protegidos foi maior, em torno de $10 \%$, em média, e houve superioridade em relação à parcela externa, de aproximadamente $50 \%$. Em resumo, diante desses resultados pode-se afirmar que existiu efeito dos ambientes protegidos nas duas épocas do ano, com pequena vantagem no inverno e que, ainda com relação ao efeito das orientações dos ambientes protegidos, quase não houve incidência no verão, incidindo pouco no inverno; de modo geral, o rendimento no verão foi superior ao rendimento no inverno, cujo $\mathrm{AP}(\mathrm{N}-\mathrm{S})$ foi o maior responsável por essa diferença.

Tabela 1. Rendimento (t.ha ${ }^{-1}$ ) da alface nos dois períodos experimentais

\begin{tabular}{lcc}
\hline Parcelas & Experimento I & Experimento II \\
\hline AP(L-O) & 87,07 & 52,32 \\
AP(N-S) & 86,76 & 47,64 \\
Externa & 58,62 & 33,34 \\
\hline MÉDIAS & 77,48 & 44,43 \\
\hline
\end{tabular}

As fases vegetativa e reprodutiva da alface são bastante influenciadas pela temperatura que, quando elevada $\left(30^{\circ} \mathrm{C}\right)$ acelera o ciclo da cultura, geralmente aumenta a produção para algumas cultivares e antecipa a fase reprodutiva (Filgueira, 1982). A alface é considerada hortaliça de inverno, entretanto, existem cultivares que produzem no verão. De acordo com Camargo (1984) a cultivar White Boston produz, na época mais fresca do ano, $35 \mathrm{t} / \mathrm{ha}$, a cultivar Brasil 48 produz em média $38 \mathrm{t} / \mathrm{ha}$, havendo caso de produtividade em torno de $62 \mathrm{t} / \mathrm{ha}$, também em época fresca, e a Great Lakes - 118, que na época mais propícia chega a produzir até $64 \mathrm{t} / \mathrm{ha}$, foi a primeira cultivar de alface com boa produção no verão.

Realmente, houve diferenças entre o rendimento dos primeiro e segundo experimentos, com evidente primazia da cultura no verão, cujos resultados não concordaram com as análise estatísticas realizadas através do teste $t$, de forma que os mesmos não diferiram significativamente.

\section{CONCLUSÕES}

1. O crescimento da alface, cultivar ELISA, demonstrou muita sensibilidade às variações de energia do meio ambiente.

2. Os ambientes protegidos no verão ofereceram as melhores condições energéticas para o crescimento, desenvolvimento e rendimento desta cultivar.

\section{REFERÊNCIAS BIBLIOGRÁFICAS}

BLACKMAN, G.E. The application of the concepts of growth analysis to the assessment of productivity. In: ECKARDT, F.E. (ed). Functioning of terrestrial ecosystems at the primary production level. UNESCO, Paris, p. 243-59, 1968.

BENINCASA, M.M.P. Análise de crescimento de plantas. Jaboticabal: FUNEP, 1988, 42 p.

CAMARGO, L.S. Alface. In: As hortaliças e seu cultivo. 2. ed. São Paulo: Fundação Cargill, 1984 p. 121-9.

CAUSTON, D.R.; VENUS, J.C The biometry of plant growth. London: Edward Arnold, 1981. 307p.

FILGUEIRA, F.A.R. Cichoriáceas: alface, chicórea e almeirão. In: Manual de olericultura: cultura e comercialização de hortaliças. 2. ed. São Paulo: Agronômica Ceres, 1982.338p.

MILTHORPE, F.L. The relative importance of the different stages of leaf growth in determining the resultant area. In MILTHORPE, F.L. (Ed) The growth of leaves. London: Butterworths Scientific, 1986. p. 141-50.

SEGOVIA, J.F.O.; ANDRIOLO, J. L.; BURIOL, G. A.; SCHNEIDER, F. M. Comparação do crescimento e desenvolvimento da alface (lactuca sativa L.) no interior e no exterior de uma estufa de polietileno em Santa Maria, RS. Ciência Rural, V.27, n.1, p. 37-41, 1997.

STOY, U. The translocation of $\mathrm{C}^{14}$ labelled photosynthetic products from the leaf of the ear in wheat. Physiology plants. V.16, p. 851-66, 1983. 